\title{
Keberhasilan ibu bekerja memberikan ASI eksklusif
}

\author{
Best practice of working mothers in providing exclusive breastfeeding
}

Intan Agustina Anggraeni ${ }^{1}$, Detty Siti Nurdiati², Retna Siwi Padmawati ${ }^{3}$

\begin{abstract}
Background: Indonesia faces double burden of nutritional problems, namely undernutrition and overnutrition. Exclusive breastfeeding may prevent infants from these kind of malnutritions. Working mothers are difficult to give exclusive breastfeeding due to some constraints and poor lactation management.

Objectives: To explore the experience of working mothers who succeeded in providing exclusive breastfeeding.

Methods: This was qualitative study using phenomenology design. It was conducted at Subdistrict of Sedayu, District of Bantul. Subjects were 13 mothers who purposively selected, work and have been successful provided exclusive breastfeeding, had children aged 6-24 months. Data were obtained through in-depth interview to the respondents and observation of lactation facilities at the working place. Data triangualation was performed through interview with husbands, baby sitters, colleagues and chairman of mother's workplace.
\end{abstract}

Results: Exploration of several information were studied, including intention to give exclusive breastfeeding, positive attitudes toward exclusive breastfeeding, perceived norms from social references, good selfefficacy, cultural aspect of breastfeeding, skills of lactation management, and environmental constraint experienced by mother. Intention of mothers during pregnancy was associated with behavior in providing exclusive breastfeeding. Intention to give exclusive breastfeeding was influenced by positive attitude and self-efficacy. There was difference in self-efficacy that influenced intention of mothers working in formal and informal sectors. Working mothers at formal and informal sectors differed in managing lactation. Despite some constraints and limited facilities mothers kept trying to provide exclusive breastfeeding.

Conclusions: Working mothers have a specific strategy to succeed in providing exclusive breastfeeding. Education, facilities, and breastfeeding policies in workplace should be given to working mothers.

KEYWORDS: exclusive breastfeeding, intention, lactation management, working mothers

\begin{abstract}
ABSTRAK
Latar belakang: Indonesia menghadapi beban ganda masalah gizi, yakni gizi kurang dan gizi lebih. Salah satu cara untuk mencegah masalah gizi pada bayi adalah dengan memberikan ASI eksklusif. Ibu yang bekerja sulit untuk memberikan ASI eksklusif karena kendala yang tidak dapat diatasi dan manajemen laktasi yang buruk.

Tujuan: Untuk mengeksplorasi pengalaman ibu bekerja di sektor formal dan informal yang sukses memberikan ASI eksklusif.

Metode: Penelitian ini merupakan penelitian kualitatif dengan pendekatan fenomenologi. Penelitian dilakukan di Kecamatan Sedayu, Kabupaten Bantul. Subjek diambil secara purposive sebanyak 13 orang. Kriteria inklusi subjek adalah ibu yang bekerja dan berhasil memberikan ASI eksklusif, memiliki anak usia 6-24 bulan dan bersedia menjadi subjek penelitian. Data dikumpulkan melalui wawancara mendalam dengan responden dan observasi fasilitas laktasi di tempat kerja. Triangulasi data dilakukan dengan mewawancarai suami, pengasuh, rekan kerja, dan pemimpin.

Hasil: Hasil penggalian informasi meliputi intensi ibu dalam memberikan ASI eksklusif, sikap positif terhadap ASI eksklusif, norma yang dipersepsikan dari lingkungan sosial, efikasi diri yang baik, budaya
\end{abstract}

\footnotetext{
${ }^{1}$ Dinas Kesehatan Kabupaten Banjarnegara, Jl. Mayjen Sutoyo No.81 Banjarnegara, e-mail: intanagustinaanggraeni@gmail.com

${ }^{2}$ Bagian Obstetri dan Ginekologi RSUP Dr. Sardjito, JI.Kesehatan, Yogyakarta

${ }^{3}$ Program Pasca Sarjana IImu Kesehatan Masyarakat Fakultas Kedokteran Universitas

Gadjah Mada, Jl. Farmako Sekip Utara, Yogyakarta
} 
menyusui, keterampilan manajemen laktasi, dan hambatan lingkungan yang dialami oleh ibu. Intensi untuk menyusui eksklusif telah dimiliki oleh ibu sejak hamil. Ibu yang bekerja di sektor formal memiliki perbedaan dalam melakukan manajemen laktasi dibandingkan dengan ibu yang bekerja di sektor informal. Ibu mengalami beberapa hambatan dan keterbatasan, namun ibu tetap berjuang untuk memberikan ASI eksklusif.

Kesimpulan: Ibu bekerja memiliki strategi tertentu untuk mencapai keberhasilan dalam memberikan ASI eksklusif. Pendidikan, penyediaan fasilitas, dan kebijakan menyusui di tempat bekerja perlu diberikan kepada ibu bekerja.

KATA KUNCI: ASI eksklusif, ibu bekerja, intensi, manajemen laktasi

\section{PENDAHULUAN}

Indonesia masih menghadapi beban ganda masalah gizi yaitu masalah gizi buruk dan gizi lebih. Berdasarkan hasil Riset kesehatan dasar (Riskesdas) tahun 2013, jumlah balita dengan status gizi buruk mencapai $5,7 \%$, gizi kurang $13,9 \%$, dan gizi lebih $11,9 \%$ (1). Masalah gizi pada balita secara langsung disebabkan oleh faktor asupan makanan yang tidak sesuai kebutuhan dan infeksi. Makanan terbaik bagi bayi di awal kehidupannya adalah air susu ibu (ASI) karena ASI mengandung zat gizi lengkap dan zat kekebalan yang mampu melindungi bayi dari risiko penyakit infeksi. World Health Organization (WHO) merekomendasikan pemberian ASI eksklusif selama enam bulan (2).

Pemerintah menargetkan cakupan pemberian ASI eksklusif sebesar $80 \%$, namun target ini belum tercapai. Berdasarkan data Riskesdas tahun 2013, hanya $30,2 \%$ bayi usia 6 bulan yang diberi ASI saja dalam 24 jam terakhir dan tidak diberi makanan pralakteal (1). Rendahnya cakupan pemberian ASI eksklusif menunjukkan bahwa tidak banyak ibu yang berhasil memberikan ASI eksklusif.

Beberapa penelitian menyebutkan bahwa status pekerjaan ibu sebagai salah satu penghambat pemberian ASI eksklusif. Penelitian di Vietnam menunjukkan bahwa ibu yang bekerja memiliki risiko 14 kali lebih besar tidak memberikan ASI eksklusif (3). Penelitian yang dilakukan di Jakarta menunjukkan hanya $32 \%$ perempuan pekerja sektor formal dan $20 \%$ perempuan pekerja sektor industri yang memberikan ASI eksklusif (4).

Bagi ibu bekerja memberikan ASI eksklusif bukan hal mudah (5). Ibu bekerja perlu memiliki sikap positif, pengetahuan, keterampilan, komitmen diri, komunikasi yang terbuka, serta dukungan sosial dan tempat bekerja agar berhasil memberikan ASI eksklusif (6). Faktor-faktor yang menyebabkan kegagalan pemberian ASI eksklusif pada ibu bekerja antara lain adanya persepsi bahwa ASI tidak cukup, kurangnya pengetahuan manajemen laktasi saat bekerja, kurangnya waktu untuk memerah ASI, fasilitas yang tidak kondusif untuk menyusui atau memerah $\mathrm{ASI}$, dan tidak ada dukungan dari pimpinan $(4,7,8)$.

Seorang ibu bekerja akan berhasil memberikan ASI eksklusif bila memiliki intensi, keterampilan manajemen laktasi, dan sedikit hambatan lingkungan (9). Intensi ibu untuk memberikan ASI saat prenatal berhubungan erat dengan durasi pemberian ASI (10). Berdasarkan hasil penelitian hanya $32,4 \%$ ibu yang memiliki intensi atau niat menyusui eksklusif berhasil mewujudkannya (11). Hal ini disebabkan oleh adanya hambatan yang tidak dapat diantisipasi serta kurangnya keterampilan yang dimiliki ibu. Keterampilan manajemen laktasi diperlukan oleh ibu bekerja untuk mengatur aktivitas menyusui dan pekerjaan.

Penelitian yang hanya berfokus pada intensi, motivasi, dan pengetahuan tidak cukup untuk membantu ibu mengatasi hambatan selama menyusui dan bekerja (8). Ibu bekerja memerlukan dukungan, edukasi dan informasi yang konsisten, realistis, dan evidence-based agar berhasil memberikan ASI eksklusif (12). Penelitian tentang pengalaman keberhasilan ibu bekerja dalam memberikan ASI eksklusif masih terbatas dan diperlukan untuk memberikan dukungan dan edukasi kepada ibu menyusui yang bekerja. 


\section{BAHAN DAN METODE}

Penelitian ini merupakan penelitian kualitatif dengan pendekatan fenomenologi yang berfokus pada pengalaman keberhasilan ibu bekerja dalam memberikan ASI eksklusif yang ditekankan pada usaha untuk memahami perilaku responden. Tempat penelitian adalah di Kecamatan Sedayu Kabupaten Bantul Provinsi Daerah Istimewa Yogyakarta. Penelitian dilakukan bersama dengan penelitian Status Gizi Ibu Hamil dan Baduta di Kecamatan Sedayu Kabupaten Bantul pada bulan April hingga Agustus 2014.

Pemilihan subjek penelitian dilakukan menggunakan metode purposive sampling. Subjek utama terdiri dari 7 orang ibu bekerja formal dan 6 orang ibu bekerja informal. Sebagai triangulasi dilakukan wawancara kepada 4 orang suami, 4 orang pengasuh anak, 1 orang rekan kerja, dan 2 orang pimpinan kerja.

Pengumpulan data dilakukan dengan wawancara mendalam dan observasi. Wawancara mendalam dilakukan kepada informan utama dan informan pendukung. Informan utama adalah ibu bekerja yang berhasil memberikan ASI eksklusif. Informan pendukung adalah suami, pengasuh anak, rekan kerja, dan pimpinan kerja. Wawancara mendalam digunakan dengan tujuan mengeksplorasi pengalaman ibu bekerja yang berhasil memberikan ASI eksklusif. Observasi dilakukan terhadap keberadaan dan kondisi fasilitas menyusui di tempat bekerja.

\section{HASIL}

Pekerjaan ibu dalam penelitian ini bervariasi antara lain: asisten apoteker di rumah sakit, karyawan bagian human resources development (HRD) di sebuah pabrik, guru bimbingan belajar, asisten dosen, sales promotion girl (SPG), tukang cuci, dan wirausaha. Sebagian besar ibu pekerja sektor informal memiliki usaha sendiri seperti berdagang dan beternak. Usia ibu berkisar antara 22-36 tahun, berpendidikan mulai dari sekolah dasar sampai perguruan tinggi, dan memiliki 1-3 orang anak.

Sebagian besar ibu pekerja sektor informal kembali bekerja setelah bayi berusia diatas enam bulan. Ibu pekerja sektor formal sebagian besar kembali bekerja sebelum bayi berusia enam bulan.

\section{Intensi dalam memberikan ASI eksklusif}

Intensi untuk memberikan ASI eksklusif sebagian besar telah dimiliki ibu sejak hamil. Tidak terdapat perbedaan yang berarti antara intensi ibu pekerja sektor informal dan formal. Intensi ibu untuk memberikan ASI eksklusif timbul setelah mendapatkan informasi dan pengetahuan dari pertemuan KP (kelompok pendukung) ibu, pelatihan pemberian ASI eksklusif, buku panduan kehamilan, tenaga kesehatan, dan internet.

Ibu yang memiliki intensi kuat mengatakan bahwa sejak hamil atau sebelum hamil sudah berniat untuk memberikan ASI eksklusif seperti kutipan berikut,

"Sejak hamil ini prinsipku sudah harus ASI eksklusif tidak boleh ditambahin apapun." (Ibu bekerja formal, fulltime, pendidikan rendah)

Adanya intensi yang kuat selanjutnya juga diwujudkan dengan upaya yang dilakukan ibu dalam mengatasi masalah yang mungkin mengakibatkan kegagalan pemberian ASI eksklusif. Masalah tersebut meliputi tidak dapat melakukan inisiasi menyusu dini (IMD), bayi kuning, ibu sakit, bayi hanya mau minum dengan dot, dan ASI tidak segera keluar setelah melahirkan. Salah satu ibu yang mengalami kondisi bayi tidak mau menyusu tetap berusaha memberikan ASI eksklusif dengan cara diperah seperti kutipan berikut:

"Jadi malah lebih berat kan kemarin. Dia nggak mau nenen langsung maunya pakai dot. Kalau malem saya tiga jam sekali tetep bangun mompa. Meskipun nggak diminum saat itu tapi mompa terus. Itu sebelum enam bulan memang dia maunya sudah pakai dot terus tapi eksklusif. Makanya kan tetep mompa nanti jam tujuh, jam sepuluh, jam satu trus jam setengah empat terus mompa." (Ibu bekerja formal, fulltime, pendidikan tinggi).

Dua orang ibu meskipun telah memiliki intensi untuk memberikan ASI eksklusif saat hamil namun memberikan makanan pralakteal karena ASI tidak 
segera keluar setelah melahirkan. Rasa kasihan kepada bayi membuat orang tua panik dan berinisiatif memberikan makanan pralakteal berupa air putih dan susu formula meskipun petugas kesehatan tidak menyarankan hal tersebut. Setelah ASI keluar ibu menghentikan pemberian makanan pralakteal dan hanya memberikan ASI saja sampai bayi berusia enam bulan. Kondisi serupa sebenarnya juga dialami oleh ibu lain. Peraturan rumah sakit yang melarang pemberian susu formula dan dukungan petugas kesehatan yang mendorong ibu untuk tetap menyusui bayi membuat makanan pralakteal tidak diberikan. Kondisi psikologis ibu yang tenang dan hisapan bayi sangat membantu memperlancar sekresi ASI.

Ibu yang pada awalnya tidak memiliki intensi untuk memberikan ASI eksklusif menyatakan bahwa akan menyusui eksklusif bila ASI-nya mencukupi. Jika sudah kembali bekerja dan ASI tidak cukup, maka susu formula akan diberikan. Adanya masalah kesehatan pada bayi dan dokter memberikan nasehat untuk melanjutkan pemberian ASI eksklusif, menyebabkan ibu berniat memberikan ASI eksklusif. Ibu lain mengungkapkan bahwa ketika anak berusia lima bulan pernah dicoba diberikan susu formula karena ASI perah hanya sedikit, namun bayi menolak sehingga baru disusui setelah ibu pulang bekerja.

Beberapa budaya menyusui yang ada di sekitar ibu seperti kepercayaan menyusui dari satu payudara karena salah satu payudara dianggap menghasilkan ASI yang pahit dan kepercayaan bayi lahir menangis minta makan tidak mempengaruhi intensi ibu untuk memberikan ASI eksklusif.

\section{Sikap, norma yang dipersepsikan, efikasi diri dan budaya dalam memberikan ASI eksklusif}

Ibu bekerja yang berhasil memberikan ASI eksklusif memiliki sikap positif terhadap ASI eksklusif. Sikap positif yang dilandasi keyakinan terhadap manfaat ASI yaitu hemat biaya, praktis, dan membuat anak tidak mudah sakit mendorong intensi ibu untuk memberikan ASI eksklusif, seperti kutipan berikut:

"Ya itu, tahu keuntungannya. Kan ASl eksklusif salah satunya untuk kekebalan itu trus untuk kecerdasan otaknyajuga. Ya mudah-mudahan untuk investasi jangka panjang lah". (Ibu bekerja formal, parttime, pendidikan tinggi).

Sikap negatif yang dilandasi keyakinan terhadap kerugian pemberian ASI tidak dimiliki oleh ibu. Kekhawatiran perubahan bentuk tubuh, rasa malu untuk menyusui di tempat umum, dan kerepotan memerah ASI tidak dirasakan oleh ibu.

Sebagian besar ibu mengatakan bahwa pemberian ASI eksklusif belum menjadi norma di lingkungan keluarga dan tetangga terutama bagi ibu yang bekerja. lbu yang bekerja di sebuah pabrik juga mengungkapkan bahwa menyusui eksklusif belum menjadi kebiasaan bagi pekerja perempuan di tempatnya bekerja. Meskipun norma yang dipersepsikan dari lingkungan sosial bertentangan dengan pemberian ASI eksklusif, ibu tidak terpengaruh dan tetap memberikan ASI eksklusif.

Beberapa hal yang membuat ibu memiliki efikasi diri akan berhasil memberikan ASI eksklusif adalah jumlah ASI yang mencukupi dan anak yang tidak rewel. lbu pekerja sektor informal merasa yakin berhasil memberikan ASI eksklusif karena memilih kembali bekerja setelah anak berusia enam bulan, sehingga tidak menyulitkan pemberian ASI eksklusif. Sementara itu, ibu yang bekerja formal merasa yakin bisa memberikan ASI eksklusif karena mendapat dukungan dari suami, rekan kerja, dan pimpinan.

\section{Keterampilan manajemen laktasi}

Ibu dalam penelitian ini telah melakukan upaya-upaya untuk menunjang keberhasilan memberikan ASI eksklusif dimulai saat kehamilan, sebelum kembali bekerja, dan saat bekerja. Ibu yang bekerja di sektor formal dan informal memiliki persamaan dalam melakukan persiapan pemberian ASI eksklusif saat hamil. Beberapa ibu melakukan persiapan dengan merawat payudara yaitu dengan membersihkan, menarik puting, dan memijat payudara agar ASI segera keluar setelah melahirkan. Ibu lain mengonsumsi sayuran seperti daun katuk dan air rebusan kacang hijau yang dipercaya dapat memperbanyak ASI. Salah satu ibu pekerja sektor formal mempersiapkan peralatan untuk memerah ASI seperti pompa ASI dan botol 
kaca karena akan segera kembali bekerja setelah cuti melahirkan.

Sebagian besar ibu pekerja sektor informal memilih untuk tidak bekerja setelah melahirkan. Ibu kembali bekerja setelah merasa anak cukup umur untuk ditinggal atau diajak bekerja. Upaya yang dilakukan ibu agar ASI lancar dan mencukupi kebutuhan bayi adalah dengan rutin mengonsumsi jamu menyusui yang disebut "uyup-uyup", sayursayuran hijau seperti daun katuk, serta madu. Sebelum kembali bekerja atau saat cuti melahirkan, beberapa ibu pekerja sektor formal mencari informasi tentang cara memerah dan menyimpan ASI kepada ahli gizi, dokter, bidan atau artikel di internet, mencoba memompa ASI, membuat stok ASI perah, dan melatih anak minum ASI perah sebagai persiapan saat harus kembali bekerja.

Ibu pekerja sektor informal yang kembali bekerja sebelum anak berusia enam bulan memilih untuk membawa anak ke toko (tempat usaha). Setiap kali menangis atau setiap dua jam, bayi akan disusui oleh ibunya, sedangkan ibu yang bekerja di sektor formal baik fulltime maupun parttime memberikan ASI perah saat bekerja dan meninggalkan anak. Frekuensi dan waktu memerah yang dilakukan berbeda-beda antara ibu yang satu dengan yang lain. Ibu yang bekerja parttime hanya memerah ASI di rumah dan tidak pernah memerah di tempat kerja karena waktu kerja yang pendek. Ibu yang bekerja fulltime memerah ASI sebelum berangkat kerja, saat istirahat, dan sebelum pulang bekerja. Saat ibu bekerja, pengasuh anak di rumah bertugas untuk memberikan ASI perah kepada bayi.

\section{Hambatan lingkungan}

Ibu dalam penelitian ini merasa tidak memiliki hambatan selama memberikan ASI eksklusif. Beberapa hal mungkin menjadi hambatan namun dapat diatasi. Hambatan tersebut terutama terkait dengan ketersedian fasilitas, jarak tempat kerja, dan jam kerja.

Dua orang ibu yang tidak memiliki lemari es di rumah untuk menyimpan ASI perah mengatasi hambatan tersebut dengan mengatur waktu untuk memerah, meminta tolong petugas kebersihan untuk mengantar ASI perah serta menitipkan ASI perah di lemari es tetangga. Keterbatasan fasilitas tidak menghentikan upaya untuk memberikan ASI eksklusif seperti penuturan berikut:

"Awalnya itu penuh perjuangan pokoknya. Di sini nggak ada kulkas, saya nggak punya kulkas. Trus awalnya nyimpen ASI itu cuma kalau pagi sebelum kerja mompa, nanti jam 10 mompa lagi. Trus sekitar jam 11 itu tak suruh nganter (ASI perah) bawa pulang, nanti istirahat itu saya mompa lagi buat agak sore, trus agak sore jam tiga itu nganter lagi. Habis itu akhirnya tak titipkan (kulkas) tetangga."(Ibu bekerja formal, fulltime, pendidikan tinggi)

Berdasarkan hasil wawancara, hanya satu orang ibu yang bekerja di sebuah rumah sakit pemerintah yang mengatakan telah disediakan fasilitas ruang menyusui untuk karyawan, sedangkan ibu lain tidak memiliki tempat khusus untuk memerah ASI. Ruangan yang dimanfaatkan ibu untuk memerah ASI adalah ruang meeting, ruang brankas, atau ruang penyimpanan barang. Karena kebijakan khusus yang mengatur jam kerja untuk ibu menyusui tidak ada, maka ibu berusaha memperoleh waktu untuk memerah ASI pada saat jam kerja dengan mengomunikasikan pada pimpinan dan rekan kerja. Jarak tempat kerja yang jauh menyebabkan ibu tidak dapat pulang menyusui, namun tetap dapat memberikan ASI karena sudah memiliki simpanan ASI perah yang diperah saat jam istirahat.

Salah satu ibu yang bekerja di rumah sakit memiliki sistem jam kerja shift, dengan jumlah jam kerja pada shift malam mencapai dua belas jam. Hal ini tidak menjadi hambatan karena adanya kebijakan pemberian shift pagi sampai bayi berusia empat bulan bagi ibu menyusui. Ibu juga merasa lebih senang bekerja saat shift malam karena dapat menemani anak pada pagi hari.

Pada kelompok ibu pekerja sektor formal, hanya satu orang yang memiliki fasilitas dan kebijakan khusus untuk ibu menyusui. Berdasarkan hasil wawancara mendalam dan observasi, ibu yang bekerja di sebuah rumah sakit pemerintah telah memiliki lingkungan kerja ramah laktasi. Rumah sakit tersebut telah memberikan hak dan dukungan kepada karyawan wanita untuk dapat 
memberikan ASI eksklusif. Fasilitas dan dukungan yang diberikan berupa edukasi tentang ASI eksklusif kepada karyawan, ruang menyusui dan freezer, serta kebijakan khusus bagi ibu menyusui.

Ruang menyusui yang ada di rumah sakit dapat digunakan oleh pengunjung maupun karyawan untuk menyusui atau memerah ASI. Berdasarkan hasil observasi, ruang menyusui tersebut terletak di dalam ruang poli anak dengan ukuran ruangan lebih kurang $4 \times 5 \mathrm{~m}^{2}$. Ruangan tersebut cukup luas dan nyaman, terdapat sebuah sofa, empat buah kursi rapat, empat buah poster menyusui, satu buah kipas angin, dan satu freezer.

Kebijakan untuk ibu menyusui ditetapkan berdasarkan surat edaran dari direktur rumah sakit tentang izin menyusui. Izin menyusui tersebut diberikan tiga puluh hari setelah masa cuti melahirkan. Pada awalnya, izin menyusui diberlakukan sampai bayi berusia enam bulan namun hal tersebut dinilai kurang efektif. Selama izin menyusui tersebut, ibu diberikan jam kerja mulai pukul 08.00 sampai pukul 12.00 agar memiliki waktu lebih banyak untuk menyusui di rumah. Aturan jam kerja shift selama izin menyusui dapat diatur sesuai kebijakan masing-masing bagian.

Ibu lain yang bekerja di sektor formal menyatakan tempat bekerjanya belum memiliki fasilitas dan kebijakan khusus ibu menyusui. Meskipun belum ada fasilitas khusus dan kebijakan tertulis, izin untuk memerah ASI dan menggunakan ruangan kosong untuk memerah ASI diberikan setelah ibu mengomunikasikan hal tersebut kepada pimpinan dan rekan kerja

\section{BAHASAN}

Hasil penelitian ini menunjukkan bahwa perilaku pemberian ASI eksklusif sesuai dengan intensi ibu. Jika ibu memiliki intensi kuat dan dapat mengatasi hambatan, maka ASI eksklusif berhasil diberikan. Hal ini sesuai dengan hasil penelitian sebelumnya yang menunjukkan bahwa intensi berhubungan signifikan dengan perilaku pemberian ASI eksklusif setelah dikontrol dengan status pernikahan, umur, dan tingkat pendidikan (13).

Ibu bekerja yang berhasil memberikan ASI eksklusif memiliki sikap positif karena mempercayai manfaat ASI terutama bagi bayi. Hasil penelitian ini mendukung hasil penelitian-penelitian terdahulu bahwa ibu memiliki sikap positif karena mempercayai ASI dapat meningkatkan imunitas bayi serta ASI lebih murah daripada susu formula $(12,14)$. Kepercayaan akan manfaat ASI terbentuk karena ibu memiliki pengetahuan dari petugas kesehatan, buku, internet atau berdasarkan pengalaman. Peningkatan sikap positif dan penurunan sikap negatif dapat meningkatan cakupan pemberian ASI eksklusif (15). Pendidikan tentang manfaat ASI penting diberikan guna meningkatkan sikap positif. Bila ibu telah memiliki sikap positif maka intensi untuk memberikan ASI eksklusif juga meningkat. Pendidikan yang difokuskan pada peningkatan sikap positif perlu diberikan terutama di awal kehamilan.

Dalam penelitian ini norma yang dipersepsikan dari lingkungan ibu cenderung tidak sesuai dengan perilaku pemberian ASI eksklusif. Hasil penelitian ini sesuai dengan hasil penelitian yang memberikan intervensi promosi ASI eksklusif dengan norma subjektif yang berasal dari lingkungan sosial tidak berbeda antara kelompok eksperimen dan kontrol (16).

Efikasi diri merupakan merupakan faktor yang paling kuat berhubungan dengan intensi dan durasi pemberian ASI (17). Dalam penelitian ini, diperoleh beberapa hal yang membuat ibu memiliki efikasi diri sehingga berhasil memberikan ASI eksklusif yaitu persepsi ASI yang cukup, bayi yang tidak rewel, belum kembali bekerja, dan dukungan sosial. Faktor jumlah ASI dan kondisi bayi seringkali mempengaruhi keputusan ibu untuk tetap memberikan ASI eksklusif atau memberikan makanan tambahan (18). Pada ibu yang bekerja informal, efikasi diri untuk memberikan ASI eksklusif adalah karena ibu belum kembali bekerja selama pemberian ASI eksklusif sehingga dengan mudah bayi dapat disusui. Kesempatan untuk selalu berada di rumah merupakan situasi yang membuat ibu merasa mampu memberikan ASI eksklusif (14). Dukungan dari suami, rekan kerja, dan pimpinan membuat ibu pekerja sektor formal merasa yakin dapat memberikan ASI eksklusif. Bantuan suami di rumah, sikap rekan kerja, dan pimpinan yang 
memberikan waktu untuk memerah memudahkan ibu untuk memberikan ASI eksklusif.

Di masyarakat Jawa, khususnya Yogyakarta kegagalan pemberian ASI eksklusif dipengaruhi oleh budaya dan kepercayaan seperti memberikan ASI hanya dari payudara sebelah kiri, hubungan seksual mempengaruhi kualitas ASI, membuang kolostrum karena kotor, dan bayi lahir menangis karena meminta makan (19). Berdasarkan hasil penelitian ini, meskipun masih ada budaya dan kepercayaan di sekitar ibu seperti pemberian air gula tajin pada bayi, bayi menangis karena ingin makan, dan membuang kolostrum karena dianggap susu basi tidak mempengaruhi intensi ibu untuk tetap memberikan ASI eksklusif.

Ibu yang bekerja di sektor formal dan informal melakukan upaya yang berbeda untuk menunjang keberhasilan pemberian ASI eksklusif. Perbedaan tersebut terutama disebabkan perbedaan waktu kembali bekerja. Ibu pekerja sektor informal kembali bekerja setelah anak berumur lebih dari enam bulan dan membawa anak saat bekerja sehingga menyusui dapat dilakukan setiap saat, sedangkan ibu pekerja sektor formal memberikan ASI perah karena tidak dapat menyusui saat bekerja. Sesuai hasil penelitian di New Zealand, ibu bekerja yang memberikan ASI berusaha untuk menyeimbangkan peran sebagai pekerja dan sebagai ibu dengan membuat stok ASI dan menjaga suplai ASI (20).

Intensi untuk memberikan ASI eksklusif tidak dapat terwujud bila ibu bekerja tidak mampu mengatasi hambatan yang berasal dari lingkungan di sekitar ibu. Dalam penelitian ini, Ibu dapat mengatasi hambatan karena mampu mengatur waktu dengan baik antara aktivitas memerah dan pekerjaan.

Hanya satu tempat kerja yang mendukung dan memberikan fasilitas untuk karyawan yang menyusui yaitu ibu yang bekerja di sebuah rumah sakit pemerintah. Dukungan tersebut dimulai dengan memberikan edukasi ASI eksklusif bagi karyawan, penyediaan ruang menyusui dan freezer, kebijakan ijin menyusui selama satu bulan, serta pengaturan jam kerja shift bagi ibu menyusui. Ijin menyusui dan pengaturan jam kerja shift ini tidak diberlakukan hingga bayi berusia enam bulan, sehingga dapat memberikan kesempatan kepada ibu menyusui untuk lebih leluasa memberikan ASI eksklusif.

Implementasi kebijakan dan dukungan bagi ibu menyusui dapat dituangkan dalam bentuk tempat kerja ramah laktasi. Konsep tempat kerja ramah laktasi dapat disesuaikan dengan kemampuan sumber daya dan finansial perusahaan. Komponen dari kebijakan tempat kerja ramah laktasi meliputi ruang atau fasilitas menyusui, kebijakan tertulis dari perusahaan (dukungan terhadap pemberian ASI di tempat kerja, cuti melahirkan sesuai UU, terpenuhinya waktu istirahat yang memungkinkan ibu untuk memerah atau menyusui), edukasi laktasi di tempat kerja (21). Tujuan diberlakukannya tempat kerja ramah laktasi adalah semua pihak di perusahaan dapat menyadari dan mendukung pemberian ASI eksklusif, memudahkan akses, dan menjamin hak ibu bekerja untuk memberikan ASI eksklusif.

\section{KESIMPULAN DAN SARAN}

Ibu bekerja berhasil memberikan ASI eksklusif karena memiliki intensi untuk memberikan ASI eksklusif sejak hamil, sikap positif terhadap manfaat ASI, efikasi diri yang baik, dapat melakukan manajemen laktasi, dan mampu mengatasi hambatan. Norma yang dipersepsikan dan budaya yang tidak sesuai dengan perilaku pemberian ASI eksklusif tidak merubah intensi ibu.

Tenaga kesehatan dan konselor laktasi hendaknya dapat memberikan edukasi kepada ibu hamil yang menitikberatkan pada peningkatan sikap dan efikasi diri agar ibu hamil memiliki intensi yang kuat untuk memberikan ASI eksklusif. Tempat kerja diharapkan dapat mewujudkan kebijakan tempat kerja ramah laktasi dengan memberikan edukasi, fasilitas ruang menyusui, dan kebijakan tertulis bagi ibu menyusui.

\section{RUJUKAN}

1. Kemenkes. Riset kesehatan dasar 2013. Jakarta: Badan Penelitian dan Pengembangan Kesehatan Kemenkes RI; 2013. 
2. World Health Organization. Global strategy for infant and young child feeding. Geneva: WHO,UNICEF; 2013.

3. Dearden K.A, Quan le N, Do M, Marsh DR, Pachon $\mathrm{H}$, Schroeder DG, Lang TT. Work outside the home is the primary barrier to exclusive breastfeeding in rural Vietnam: insights from mothers who exclusively breastfed and worked. Food and Nutrition Bulletin 2002; 23 Suppl 4:101-8.

4. Basrowi R. Pemberian ASI eksklusif pada perempuan pekerja sektor formal [Tesis] Magister Kedokteran Kerja Fakultas Kedokteran Universitas Indonesia; 2012.

5. Gatrell CJ. Secrets and lies: Breastfeeding and professional paid work. Social Sciences and Medicine 2007; 65:393-404.

6. Hirani, SAA; Karmaliani, R. The experiences of urban, professional women when combining breastfeeding with paid employment in Karachi, Pakistan: a qualitative study. Women and Birth 2013; 26:147-51.

7. Riordan J. Breastfeeding and Human Lactation. Boston: Jones and Bartlett Publishers; 2010.

8. Glenn JS. Knowledge, perceptions, and attitudes of managers, coworkers, and employed breastfeeding mothers. American Association of Occupational Health Nurses Journal 2008; 56(10):423-31.

9. Fishbein M, Cappela JN. The role of theory in developing effective health communications. Journal of Communication 2006; 56:S1-S17

10. DiGirolamo A, Thompson A, Martorell R, Fein S, Strawn LG. Intention or experience? predictors of continued breastfeeding. Health Education \& Behavior 2005; 32(2):208-26.

11. Perrine CG, Scanlon KS, Li R, Odom E, Laurence M, Strawn G. Baby-friendly hospital practices and meeting exclusive breastfeeding intention. Pediatrics 2012; 130(1):1-7.

12. Moore ER, Coty MB. Prenatal and postpartum focus groups with primiparas: breastfeeding attitudes, support, barriers, self-efficacy, and intention. Journal of Pediatric Health Care 2006; 20(1):35-46.

13. Bai YK, Middlestadt SE, Joanne Peng CY, Fly AD. Predictors of continuation of exclusive breastfeeding for the first six months of life. Journal Human Lactation 2010; 26(1):26-34.

14. Bai YK, Middlestadt SE, Joanne Peng CY, Fly AD. Psychosocial factors underlying the mother's decision to continue exclusive breastfeeding for 6 months: an elicitation study. J Hum Nutr Diet 2002; 22:134-40.

15. Mutuli LA, Walingo MK, Othuon LA. Psychosocial factors influencing breastfeeding behavior of mothers attending home-based clinics in the Western Kenya. International Journal of Multidisciplinary Educational Research 2012;1(1):45-54.

16. Ryser FG. Breastfeeding attitudes, intention and initiation in low income women: the effect of the best start program. Journal Human Lactation 2004; 20(3):300-5.

17. DeJager E, Broadbent J, Tyszkiewicz MF, Helen $S$. The role of psychosocial factors in exclusive breastfeeding to six months postpartum. Midwifery 2013; 07(008):1-10.

18. McInnes RJ, Hoddinott P, Britten J, Darwent K, Craig LCA. Significant others, situations and infant feeding behaviour change processes: a serial qualitative interview study. BMC Pregnancy and Childbirth 2013; 13(114):1-13.

19. Widaningsih. Faktor penentu pemberian ASI eksklusif pada pengguna kontrasepsi hormonal dan non hormonal. Universitas Gadjah Mada. Yogyakarta; 2013

20. Payne D, Nicholls DA. Managing breastfeeding and work: a Foucauldian secondary analysis. Journal of Advanced Nursing 2009; 66(8):181018.

21. Asosiasi Ibu Menyusui Indonesia (AIMI). Lingkungan kerja ramah laktasi, pedoman untuk perusahaan; 2012. 